\title{
The College: A Decade On
}

We invited Martin Roth, Linford Rees, and Desmond Pond, Past-Presidents who held office during the first ten years
since the College's inception, to contribute their personal impressions of the College's first decade.

\section{Professor Sir Martin Roth (1971-1975)}

An element of personal selection is essential in the writing of history. One can do no more than cast an eye over the records of meetings and decisions, achievements and conflicts, struggles and defeats, victories and frustrations. It cannot all be reproduced. And after a mere ten years it is difficult to sift what is ephemeral from that which will prove of lasting and fateful importance.

The months that elapsed between the granting of our Charter after years of negotiation with the Privy Council and the formal inauguration of the College were often darkened by an acrimonious dispute with a body of able, talented and articulate psychiatrists in training who had created their own organization ('APIT'). The young men were confronted with the prospect of yet one more examination which appeared to them to be superfluous. Those who had already obtained one or more postgraduate qualifications were understandably aggrieved. They felt betrayed by their seniors who seemed to be pulling up the ladder with unashamed complacency. No simple solution or compromise seemed possible. The College was committed under the Charter to establish a Membership examination in psychiatry as soon as possible after it had been granted; the juniors threatened to boycott it. There could not have been anyone among those elected to office within the College who went to our Inaugural Meeting without a certain apprehension.

As I looked round at the audience in the large lecture hall of the Royal College of Physicians, where the meeting was held, it was heartening to observe that those who had come spanned a wide range of specialties and philosophies within psychiatry. There were many stalwarts of the old RMPA, some six ex-Presidents among them. But there was a sprinkling of distinguished British psychoanalysts, some members of the staff of the Tavistock Clinic, a few representatives of the Department of Health and some colleagues who had come from afar. I have to mention Henry Dicks, whose loss we continue to feel. He was a born conciliator whose deep generosity of spirit smoothed many paths for us in the early years.

A demonstration of protest had been expected and after my induction it was with some anxiety that I began the
Charter Address. The sense of historic occasion and of common purpose were to prove stronger than the factional grievances.

To try to pour oil on the troubled waters of the Membership I had selected a historical account of the competitive examinations for civil service appointments in Imperial China. Acute mental disorder and sudden death were not uncommon among the 10 to 12,000 candidates whe gathered for the ordeal which usually continued for a number of days. But the sealed entrance gates were not to be opened even in the event of the demise of the Grand Examiner. His corpse would have had to be hoisted over the high wall that surrounded the examination precinct. By the time I reached the blank papers and copies of their last will and testament handed in by some candidates whose minds had been deranged by stress, sombre faces had melted and I was barely audible above a new noise beginning to rock the hall. I got as far as the case of the Grand Examiner whose reason became unhinged and who tore up the papers handed in and bit and kicked those who approached him until he was finally secured and bound hand and foot to his chair. By then the whole assembly, President, Grand Examiner, Candidates, Deans and Council members were helpless for some minutes. We laughed until we wept. The air had cleared and tension was defused. Immediately after the Maudsley Lecture in the afternoon, a frank and open discussion began in which grievances were aired and concessions were made regarding exemptions from fees for the examination. Meetings and negotiations continued for months, but we never looked back. We all learned something about the healing effects of laughter.

Some other lessons for the future that can be learned from this conflict are worth pondering. Neither side was entirely right. The painful dilemma was resolved more by a spirit of co-operation and goodwill than by force of argument. But the underlying problems were not wholly resolved and they remain with us today. The Membership examination and the approved courses of training and schemes of rotation linked with it have undoubtedly helped to raise standards of professional training for a psychiatric career. But whereas

\section{Thank you}

We should like to take this opportunity of thanking all our contributors to the Bulletin in 1981. We are especially grateful to Dr Walk for his invaluable help and for devoting so much of his time to assistance in all aspects of the

Bulletin. Our special thanks also to Alison Campbell who fulfils her tasks as Editorial Assistant and 'much else' not only efficiently, but with enthusiasm and zest.

SIDNEY BLOCH \& AlAN KeRR 
previously those who had embarked upon it substantiated their claims in their own way, there is some danger that every entrant will be set upon the same course. A move into a different specialty or unit every six months creates some danger of fragmentation. It requires a long exposure for the basic clinical skills of a psychiatrist to develop in depth. Inflexible schemes for training also tend to discourage and impede scientific inquiry during the years when the capacity for original thought is at its peak. Although after discussions with the Medical Research Council we allowed exemptions more generous than most other Colleges were prepared to concede to those who opted to devote a period to clinical research, few trainees seem prepared to risk sidestepping off the ladder of professional promotion to do their own thing. The phenomenon is world-wide and just as evident in Australia and the USA, for example, as in this country. Everywhere the proportion of research grants allocated to clinically qualified applicants as compared with those trained in one of the basic sciences is in decline. A solution to this problem will have to be found if psychiatric science is not to wither.

The value of the contribution made by the now well-established programme of Approval visits to all hospitals that wish to be recognized for training is indubitable. The Approval Exercise was set in motion within a remarkably short period, mainly through the efforts of Ken Rawnsley. Within less than three years more than half of the training centres had been visited and assessed, with the aid of flexible and realistic criteria which were gradually to be made more stringent. Regional authorities were swift to respond to the comments and criticisms of visiting teams. In consequence. staffing and standards of clinical care benefited, together with training facilities. The reports received by the Court of Electors provided in return detailed information about the therapeutic programmes developed and the standards achieved within the mental health services of the United Kingdom. The insights thus obtained enabled the College to refine its ideas for planning of the psychiatric services of the future and so to enhance the quality of the contribution we were able to make in the many discussions into which we entered with the Department of Health. These took the form of both informal private talks and public meetings.

The representatives of psychiatry in the United Kingdom have been given unprecedented opportunities to bring their expertise to bear upon the shaping of policies concerning mental health in this country.

The first joint conference of the DHSS with the College at the Institute of Psychiatry in October 1972 was attended by Sir Keith Joseph, Sir George Godber and other representatives of the Department. The discussions ranged far and wide and continued at the follow-up meeting in March 1973.

When one reads the reports of these meetings it is apparent that in the eight and a half years that have elapsed little has changed. The questions formulated from the Chair in March 1973 are still germane and now more urgent.
Perhaps the Department is now less confident that large, traditional mental hospitals can be phased out in the foreseeable future. And consultants in charge of psychiatric units in general hospitals are probably less certain in their view that a fully comprehensive psychiatric in-patient service can be offered by a general hospital unit of $40-50$ beds. We are still unable to judge whether large mental hospitals will survive in the long term or to prescribe a remedy that will prevent them from becoming isolated repositories for chronic cases. Morale within many of them is low and staff difficult to recruit. The situation seems healthier in Scotland. We have still to define the scope and limitations of general hospital psychiatric units and to discover means for establishing closer links between them and the larger hospitals for the purpose of therapy and training. The community still does not care enough, and in a period of economic stringency new strategies will have to persuade it to do so.

Effective and viable services for those suffering from alcoholism and personality disorder, and for the rising tide of psychogeriatric patients are still lacking in most parts of the country. And where is psychiatric research to be conducted in the future? There is no space, time or opportunity in the thinly staffed general hospital units whose doors incessantly revolve. The refractory problems of psychiatry continue to challenge us in the large mental hospitals where the problems of chronic schizophrenia and the disorders of the aged cry out for scientific investigation. But the research units which flourished in some six or seven of these hospitals twenty years ago have all vanished or are about to be wound up, and their sadly depleted staffs are hard pressed.

The Joint Committee on Higher Psychiatric Training composed of representatives drawn from the Royal College and the Association of University Teachers of Psychiatry got off to a brisk start in 1973. Although the President of the College was the first Chairman, the committee could not have registered a fraction of the achievements in getting specialist sub-committees organized and Approval visits initiated without the competence, zeal and energy of Henry Walton who was later elected to the Chair. Few of those who have had the opportunity of observing its teams at work or have studied the reports of the committee will have been left in any doubt about the contribution it has made to elevating and rationalizing higher training in psychiatry.

The history of the events associated with the acquisition of our present premises at 17 Belgrave Square deserves a short book on its own. But it cannot be written for some years ahead. We were fortunate in our sponsors, Lord Goodman and Lord Rayne in particular, and also in the supportive attitude of Sir Keith Joseph, who gave us a great deal of guidance and encouragement. In 1973 our lease at Chandos House was due to expire and we understood there could not be more than a few months' reprieve. We bid for a number of buildings, including the old premises of the Charing Cross Hospital Medical School. But we were babes in the wood and outwitted by powerful and serpentine competitors at 
every turn. Towards the end of 1973 a crisis concentrated our minds wonderfully. The Foundation which had tentatively given us $£ 100,000$ at the beginning of the year to explore the possibility of establishing a home for the College announced that their offer would be withdrawn unless we had completed a purchase in one or two months. Some weeks of frenetic and intensive effort followed. In the end the last of five bids succeeded but we were some $£ 700,000$ short of the purchase price. We had to decide whether we were justified in raising a loan of nearly three quarters of a million, guaranteed as it was by our generous sponsors. The anxiety of members of the Appeal Committee was painful to behold. But after a brief sharp debate, we unanimously made the only possible decision. This first stage in the establishment of our College was recently completed when we were at last able to honour a pledge we had made to use one of the benefactions given us to convert the dark, dirty and desolate basement into its present splendour. The rooms thus created have been appropriately named the 'Warren Suite'.

We have recently resolved to devote the next stage of our Appeal to the acquisition of funds for promoting the kind of scholarly, scientific and educational work which the College is alone able to undertake. The first phase has taught us that funds come almost entirely from personal contacts. And we look to the Divisions to help us in this quest to advance the causes for which the College stands within each Region as well as in the country as a whole.

Ten years ago the still small voice of the Royal Colleges on national bodies such as the Joint Consultants Committee and Standing Medical Advisory Committee was often rendered inaudible by the thunder of more affluent and politically powerful organizations. There was a Conference of Royal Colleges confined to the three oldest bodies. Their Presidents would confer the night before the meeting of the Joint Consultants Committee, to be joined later by Presidents of a second division of lesser bodies among whom we were included. It became increasingly plain that there was a compelling need for unity. The Colleges and Faculties, concerned first and foremost with the promotion of highest professional and scientific standards in medicine and the protection of its ancient ethos, needed to speak with one voice. Our arguments prevailed and the Conference of Royal Colleges and Faculties now represents all these bodies, old and new. The election of Desmond Pond, our last President, to the Chair of the Conference was a well earned personal tribute to him and an honour to our College. He particularly promoted, among other activities, the continuing dialogues with the Royal College of General Practitioners. Our links with other medical bodies have been greatly strengthened during the decade by the efforts of Desmond Pond and Linford Rees, who became President of the British Medical Association after completing his term as our own President in 1978.

The theory and practice of psychiatry draw inspiration from many quarters, the behavioural and social as well as biological sciences. But the origins of our profession are historically rooted in medicine, and medical training is a bedrock on which skills and insights unique to the profession of psychiatry are established. Denied the link with medicine, psychiatry loses its raison d'être and divests itself of its claim to leadership and ultimate responsibility for the care of patients. This principle the College has repeatedly reaffirmed in the past decade, and there may be increasing need to defend it in the years to come. There are other reasons for maintaining the closest links with medicine. It is my belief that the clinical gifts at the disposal of a well trained psychiatrist should in future permeate the practice and the theory of all the professions concerned with healing.

The summer of 1973 saw a mounting volume of criticism of the Soviet Union for its treatment of political dissenters. Some had been committed for long periods to psychiatric hospitals where they had been subjected to humiliating and repressive measures and inappropriately treated with tranquillizing drugs, while others who had disclosed this abuse or protested against it had received prison or labour camp sentences. The College was subjected to criticism in the course of a long correspondence in The Times. In particular, the Secretary-General of International Pen Club attacked us for participation in the WPA-sponsored Schizophrenia Conference in the Soviet Union. We had played no part in arranging this conference, and as it seemed essential to protect the College's good name I wrote on my own responsibility to The Times on 4 September and the Guardian on 8 September making this plain and expressing our repugnance at the treatment to which political dissenters had been subjected. My action was later endorsed by Council. The letter in The Times drew an immediate response from TASS which published an interview with a distinguished Soviet psychiatrist on 7 September. He accused me of trying to '... galvanize an anti-Soviet lie that had long been a propagandist corpse'. He also expressed the view that the '... facts did not interest Roth at all'. The psychiatrist in question provided no factual information in the article nor did he do so in the subsequent correspond ence in which we tried to elicit an account of the diagnoses and treatments used and the rationale that informed them; so his remarks remained enigmatic.

In the years that followed, our efforts in concert with those in other countries probably played some part in securing the release of Bukovsky and Plyushch among others. But all attempts to try to shed light on the situation through correspondence elicited only indifferent or angry and defensive responses. At the International Congress of Psychiatry in Honolulu in 1977, condemnation of Soviet abuse of psychiatry by the General Assembly of the World Psychiatric Association failed to modify the attitude of the Soviet delegates. At the concluding session they launched a bitter attack upon those who supported the vote of censure, accusing them of engaging in ill-concealed anti-Soviet political propaganda on behalf of capitalist interests. 
Was the College justified in making common cause with psychiatrists in different parts of the world in criticizing the use of psychiatry for the suppression of dissent in Russia and elsewhere, or was it going beyond its proper domain? I believe we had no alternative to the course of action adopted. We were confronted with an issue of principle we could not burke. Critics such as Thomas Szasz would have it that psychiatry constitutes in all countries a sordid conspiracy against the freedom of ordinary people and is utilized by the powers that be in order to label, invalidate and repress all forms of dissent. Psychiatrists have repudiated such views. They uphold the inalienable right of the individual to dissent and deviate from the conventional moral and political beliefs of the society in which they live. No form of deviance, as such, constitutes illness. The human mission and scientific purpose of psychiatry is to treat or mitigate mental suffering and, as van Praag has shown, deviance may be a secondary consequence of psychiatric disorder but never in itself a valid criterion for its diagnosis. If we were to define the ethos of psychiatry, there was no alternative to the actions we took and must continue to take against those who misuse it.

Anyone who has read Bukovsky's To Build a Castle or has had an opportunity of hearing Plyushch describe his experiences is not likely to be left in doubt that the treatment meted out to them was a slur upon psychiatry's good name which all those who practise must try to expunge.

I owe a debt of gratitude to Tom Main who devoted time and energy in the midst of an extremely busy professional life to occupy the roles of Vice-President, member of the Executive and Finance Committee and Council, during the greater part of my term of office. Wilfred Warren's wisdom, dedication and skill in the role of Treasurer and second Vice-
President made a contribution of inestimable value to the work of the College, continuing as financial wizard and watchdog tasks he had undertaken for the RMPA over a number of years. We were fortunate to have Ken Rawnsley, now our President, as our first Dean, and Morris Markowe's sage and judicious mind at work in the office of Registrar. Our gratitude is also due to the pioneer visiting Approval teams who undertook their difficult and delicate task with tact and discernment. Eliot Slater, who was the main architect of the British Journal of Psychiatry as a scientific and clinical journal of world wide influence, I have already paid tribute to in 11 years as Editor, teacher and friend of a multitude of contributors to our Journal. Edward Hare, who succeeded him, brought to bear not only an incisive critical mind but an unexpected business flair on his editorial tasks and for the first time made the Journal financially profitable. The furnishing of our library has been made possible through a generous grant from one of the Foundations, and it is now under the aegis of Henry Rollin, with for the first time has the aid of a professional librarian. Miss Natalie Cobbing's loyal and devoted service, her experience of the College's affairs over many years and her unfailing memory have proved of great value to the College during the entire decade. We must be specially grateful to members of the small Executive and Finance Committee who travel long distances each month or more frequently to attend meetings to decide matters that are often of fateful importance for the College's future. There were other officers, councillors and friends too numerous to list in a short article, who contributed to make the early formative years of the College happy and creative, thus laying solid foundations for its humane constructive work in the years of maturity and venerable old age ahead.

\section{Professor W. Linford Rees (1975-1978)}

Our Founders (Hitch, Gaskell, Thurnam and others), who established the Association of Medical Officers of Asylums and Hospitals for the Insane, started an evolutionary process which is continuing to the present day.

After 24 years, this first Association became The Medico-Psychological Association. In 1926 this received its Charter and the title 'Royal', and in 1971 it became The Royal College of Psychiatrists.

Ten years is a small part of the total life of the College and its predecessors, but its achievements during the past decade have been remarkable. Francis Pilkington and Martin Cuthbert, the last two Presidents of the RMPA, together with its General Secretary, Ben Monro and the Registrar, William Sargant, paved the way for the transformation helped by many other people, among whom special mention should be made of John G. Howells.

At the outset a great deal of preparatory work was done by the transitional Council and Court of Electors, including the establishment of criteria for admission to Foundation Membership and Foundation Fellowship.

At the first Annual Meeting in November 1971, Sir Martin Roth was inducted as its first President. His term covered a period of nearly four calendar years; and the outstanding event of this period was the aquisition of 17 Belgrave Square as the College headquarters. We owe this important development to the work of the Appeal Committee, chaired by the President, with the invaluable support given by its sponsors and benefactors, led by Lord Goodman and Lord Rayne, and the substantial support given by the membership.

The lease of the house was bought from the Institute of Metals; as one member remarked, this was very convenient since all that was needed was the addition of one letter to make it the 'Institute of Mentals'!

During the second phase of three years, whilst I was President, the finances of the College became well established, 